\title{
Article
}

\section{Effect of Artificial Aging Treatment and Lubrication Modes on the Machinability of A356 Cast Alloys}

\author{
Mohamed Amine Alliche', Abdelhakim Djebarad,*, Yasser Zedan ${ }^{1}$ and Victor Songmene ${ }^{2}$ \\ 1 Laboratoire de Mécanique et Matériaux Avancés (LM²A), Department of Mechanical Engineering, ENPC, \\ Constantine 25 000, Algeria \\ 2 Laboratoire d'ingénierie des produits, procédés et systèmes (LIPPS), Departments of Mechanical \\ Engineering, ÉTS, Montreal, H3C 1K3, Canada \\ * Correspondence:abdelhakim.djebara@enp-constantine.dz
}

\begin{abstract}
This article discuss the effects of heat treatment and lubrication modes on the machinability of an A356 alloy (Al-Si-Mg); the alloy is studied as-received, with solution heat-treated alloy (SHT) as well as with an alloy that is solution heat-treated and then aged at 155, 180 and $220^{\circ} \mathrm{C}$. In the course of machinability evaluation, several criteria including cutting force, surface roughness, tool wears and burr analysis (chip) were studied. The results and analysis in this work indicated that the selected machinability criteria are important and necessary to effectively evaluate the machinability of A356 alloys. The machinability of both materials and tools were estimated in terms of cutting force, chip thickness ratio and burr formation, flank wear and roughness. The effects of different cutting parameters (cutting speed and feed rate) and lubrication modes (dry, mist and wet) on the machinability of the A356 cast alloy were also examined. The influence of heat treatments on the burr formation and surface quality was clearly revealed by the experimental results. Experimental work revealed that cutting forces were influenced significantly by aging and cutting speed. However, the different aging at 155,180 , and $220^{\circ} \mathrm{C}$ and the cutting speed significantly affected the machinability of the A356 cast alloy. The results obtained show that a better drilling performance in terms of surface quality occurs at a high feed rate, with dry drilling and artificial aging at $\mathrm{T} 6$.
\end{abstract}

Keywords: aluminum alloys; artificial aging; drilling; surface quality; cutting fluid; burr formation

\section{Introduction}

Using aluminum alloys as a replacement for steels is expected to lead to great progress in saving energy, life-cycle cost and recyclability [1]. However, the low strength of aluminum alloys as compared to steel is the main reason industries cannot apply them in many structures which require a higher strength and stiffness, while, in some structures which do not have a high requirement for mechanical property, aluminum alloys have been applied widely. Aluminum alloys have progressively attracted increased attention from many specialists as promising materials for application in the automotive and aeronautical industries [2].Advanced aluminum materials are widely used in the automotive industry for the manufacturing of several types of parts, such as the vehicle's structure and wheels [3]. In those cases, increasing the machinability of aluminum alloys becomes an essential task. This implies that it is necessary to control the formability and the strength of aluminum alloys for industrial applications [4].

Machinability is defined for a specific application by various criteria: tool life, surface finish, chip evacuation, material removal rate and power of the machine tool. The chemical composition, structural defects and alloying elements have been shown to significantly influence the machining performance of aluminum alloys [5]. The Al-Si-Mg alloy has good mechanical and physical properties. This alloy offers good corrosion resistance, is easy to machine, is heat treatable, has 
excellent castability and has good recycling possibilities [6]. The drilling processes of Al-Si-Mg alloys are executed with great difficulty. Due to plastic deformation during machining, this alloy tends to form burrs and adhere to the tool [7]. Burrs are formed on the part's edges [8]. The output of burrs is important as they is more difficult to remove because of their large sizes, which require higher precision deburring and edge-finishing tools. Therefore, more attention has been paid to drilling exit burrs than entrance burrs [9]. The product quality without burrs is an important parameter in drilling, that increases reliability and performance. Limiting the burr formation at the source is a better solution than a subsequent finishing operation [10]. Sofronas summarized several cutting factors that contribute to drilling burr formation [11]. According to his survey, the most effective factors are drilling geometry, the material of the workpiece, machining rigidity, drilling condition and cutting fluids. Hasegawa et al examined burr formation based on cutting speed, feed rate, and drill geometry [12]. According to Hesegawa et al., there is a formation of small burrs at high speeds. Furthermore, it was exhibited that a lower feed rate lead to decreased burr size. Pande and Relekar determined that a smaller burr height results from the use of a smaller diameter of drill tool [13]. This study was based on the influence of feed rate, length to diameter ratio, drill diameter and material hardness on burr thickness and height. The study of the drilling burr formation morphology by Ko and Lee showed that the burr thickness does not depend on the feed rate. On the other hand, the material properties have large effects on the burr thickness compared to the feed rate [14].

In the literature, the role of artificial aging has extensively reported in relation to the alloys' machinability $[15,16]$. It was also found that minimum values of exit burrs are due to the material hardness in the range of 130-140 Brinell hardness number (BHN). According to Gillespie, hard materials tend to reduce the size of burrs because the material is more likely to crack close to the cutting edge [17]. Similar findings to Gillespie were found by Ko [18]. The Al-Si-Mg series includes the A356 aluminum alloy, which can be heat treated. Magnesium combines with Si to form a hard phase by $\mathrm{Mg} 2 \mathrm{Si}$ precipitation due to the magnesium content in these alloys [19]. Heat treatment increases the hardness and improves the surface finish of the workpiece by reducing the built-up-edge (BUE) formation on the tool. In drilling and turning operations, any increase in the cutting temperature is critical to tool life since it produces excessive accelerated heat-causing wear-out of the edge [20]. Typical automotive machining techniques, however, usually require a minimum of workpiece hardness in order to avoid potential complications associated with built-up edge (BUE) on the tool. A minimum hardness of $80 \mathrm{BHN}$ is desirable for most automotive machine shops [21,22]. As a courtesy to this observation, the 319 aluminum alloy intake manifolds are often aged to the $\mathrm{T} 5$ temper, and the 356 aluminum alloy manifolds usually require full artificial aging treatment to the T6 temper $[15,23]$.

To overcome the restrictions imposed against wet machining, special attention has been paid to use of dry machining in recent years. In addition, the use of cutting fluids increases the machining cost to approximately $16 \%$ of production costs and degrades the environment. However, sometimes wet machining is still used, especially under extreme cutting conditions when a better surface finish quality and higher machining efficiency are required. In recent years, a new technique known as minimum quantity of lubricant (MQL) has been proposed to insert the fluid/lubricant in the form of an aerosol spray at a rate not exceeding $100 \mathrm{~mL} / \mathrm{h}$ (atomized format to form fine droplets) [24,25]. The successful applications of MQL in drilling operations are reported in the literature [26-28]. It has been found that the MQL process can reduce the cutting forces, friction and wear compared to dry cutting [29]. Sukhpal shows that the MQL reduces the drilling torques and thrust forces as compared to other coolant-lubrication conditions [30].From the effectiveness of the MQL on machining imperfections reduction, it is clear that additional studies are still required to select the appropriate cutting conditions to reduce machining imperfections over a limited range of process parameters [31]. Sreejith and Ngoi show the effects of the flooded coolant, MQL and dry conditions on surface roughness, tool wear and cutting forces in turning aluminum alloy [32]. It was established that MQL can replace the flooded coolant condition when properly employed. 
Machining parameters such as tool type, depth of cut, cutting speed, feed rate, ductility (A \%), hardness (HBN, HRE), and strength $\left(\mathrm{R}_{\mathrm{m}}\right)$ are the most important elements to control the machinability of aluminum alloys (fundamental and extrinsic) [33]. To better analyze the effects of heat treatment methods on machinability attributes, the parts were machined under controlled cutting conditions after heat-treatment in order to produce different precipitation shapes. The main objectives of this study were focused on evaluating the influence of cutting fluid and machining conditions on the surface roughness, cutting force and burr formation when drilling A356 under several heat treatment conditions. This would enable us to better define the machinability of A356.

\section{Materials and Methods}

Machining tests were conducted on a Huron HSC KX8 CNC Milling Machine(Huron Canada, Longueuil, Canada, $50 \mathrm{~kW}, 28,000 \mathrm{rpm}, 50 \mathrm{Nm}$ ) using uncoated high-strength steel (HSS) twist drills (10 mm stub drill bright finish with $118^{\circ}$ degree conventional point). A set of similar drilling tools were used during the tests to ensure the reliability of the geometry and the properties of the microstructure. The work materials were A356 cast alloy blocks $\left(300 \times 100 \times 20 \mathrm{~mm}^{3}\right)$, fixed on a machining device specially designed for this purpose (Figure 1). All samples were heat-treated at $540{ }^{\circ} \mathrm{C}$ for an 8 hour period and then quenched in warm water at $60^{\circ} \mathrm{C}$. The chemical composition of the work part used (A356) is presented in Table 1.

Table 1. Chemical composition of A356 alloy

\begin{tabular}{ccccccccc}
\hline As-cast state & $\begin{array}{c}\text { Silicon } \\
\text { Min-Max \% }\end{array}$ & $\begin{array}{c}\text { Copper } \\
\text { Max \% }\end{array}$ & $\begin{array}{c}\text { Magnesium } \\
\text { Min-Max \% }\end{array}$ & $\begin{array}{c}\text { Fe } \\
\text { Max \% }\end{array}$ & $\begin{array}{c}\text { Manganese } \\
\text { Max \% }\end{array}$ & $\begin{array}{c}\text { Zinc } \\
\text { Max \% }\end{array}$ & $\begin{array}{c}\text { Ti } \\
\text { Max \% }\end{array}$ & Al \\
\hline A356 & $6.5-7.5$ & 0.2 & $0.245-0.25$ & 0.2 & 0.1 & 0.1 & 0.2 & Balance \\
\hline
\end{tabular}

The samples were received in an as-cast state and considered to be the T0 state, and were then divided into five groups as follows:

- Two samples in as-cast state, this is T0 state;

- Two samples in T4 state, which is a solution that has heat-treated "SHT", and is more quenched;

- Two samples in T61 state, with a solution that has heat-treated "SHT", more quenching and more artificial aging at $155^{\circ} \mathrm{C}$ for 5 hours;

- Two samples in T62 condition, which is a solution with heat-treated "SHT", more quenching and more artificial aging at $180{ }^{\circ} \mathrm{C}$ for 5 hours;

- Two samples in T7 condition, a solution with heat-treated "SHT", more quenching and more artificial aging at $220^{\circ} \mathrm{C}$ for 5 hours. 


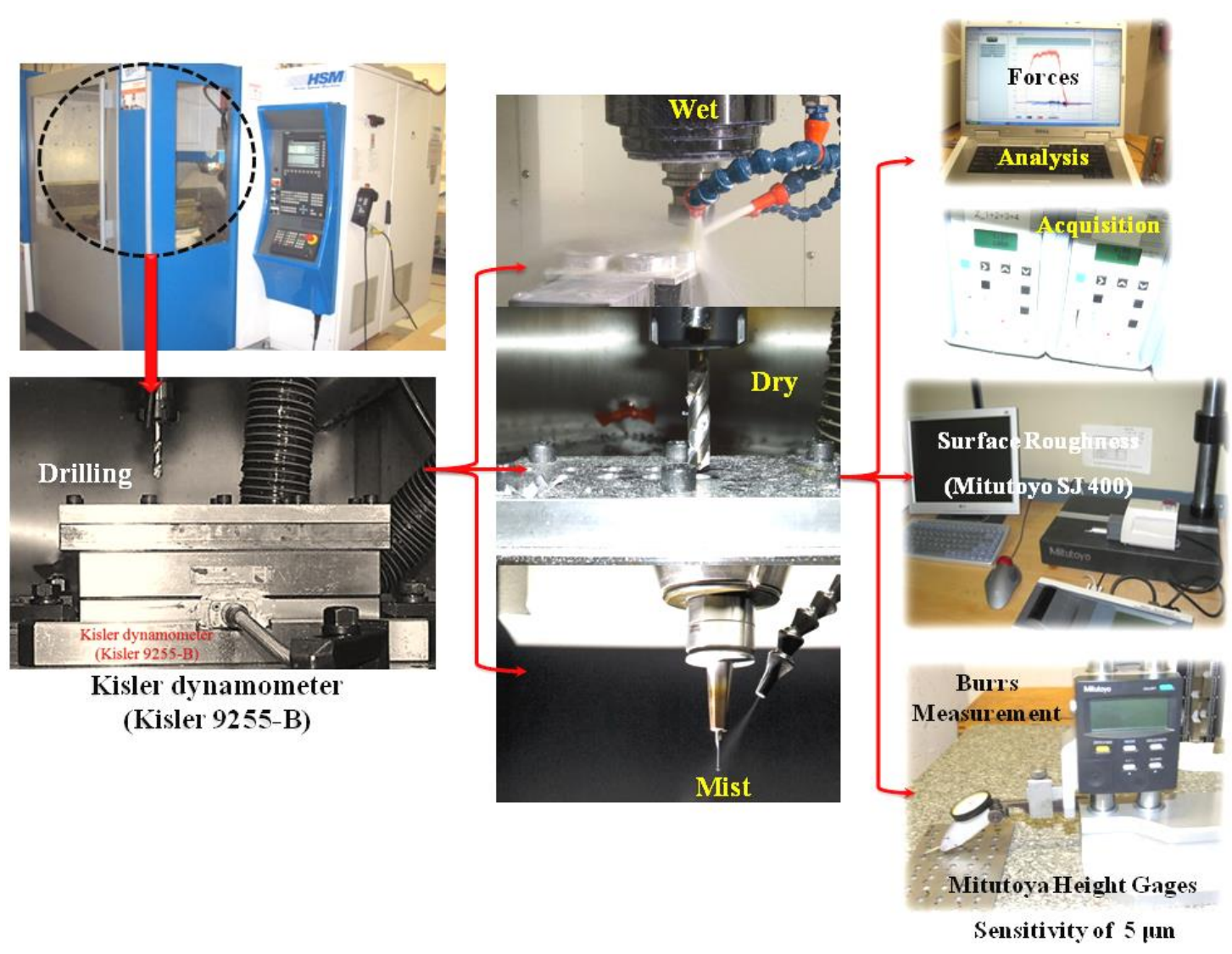

Figure 1. Experimental setup used

The cutting forces were measured using a dynamometer table (Kistler 9255B). The cutting forces were then amplified and analyzed using the sampling frequency of $48 \mathrm{kHz}$. The drilling performance parameter is estimated relative to the total drilling force $(\mathrm{Ft})$. The average cutting force generated during the drilling of each hole was calculated within the time period corresponding to the drilling cycle. The surface roughness of each hole was estimated according to the Ra parameter using the Mitutoyo SJ 400 profilometer (Mitutoyo America Corporation, California, USA). The samples were cleaned with ethanol and ultrasonically cleaned to examine the surface of the drilled holes. The surface roughness was recorded at four dissimilar positions $\left(90^{\circ}\right.$ apart) and the measurements were repeated twice at each point. The average value was used for analysis purposes in this study.

Chips were studied for each experiment, after preparation for further metallographic examinations. The Hitachi scanning electron microscope (SEM) S-3600N (Hitachi High Technologies America, Texas, USA) was used to capture the high-resolution images of the chip morphologies that were collected for each experiment and tool wear. To that end, the samples were cleaned in an ethanol bath and ultrasonically cleaned before being transferred to the SEM microscope. The burr height was measured using Mitutoyo height gauges $( \pm 5 \mu \mathrm{m})$. To measure the burr height, the gauge indictor was first placed on the datum surface and then measured to the top end of the burr. The distance between the two measurements was considered as the burr height. The average value of the measurements was obtained with a four-fold repetition, and then it was used as the burr size in experimental analysis. The burr formation morphology was monitored using a high-resolution optical microscope.

In the current research, drilling tests were performed for various coolant application modes, at different cutting speeds and feed rates. To formulate a relationship between the machining responses and cutting parameters and their interaction effects, a full factorial design was used to generate different experiments' combinations. To that end, three lubrication modes and five heat-treatment methods were used in combination with three levels of cutting speed and feed rate. 
The factors studied and their levels are summarized in Table 2. The drilling tests were replicated four times for each condition. In total, 135 experiments were conducted to complete the study.

Table 2. Design of experiment factors and their levels

\begin{tabular}{|c|c|c|c|}
\hline Variable parameter & Min limit & Intermediate limit & Max limit \\
\hline A: Rotational speed(rpm) & 2000 & 6000 & 10,000 \\
\hline A: Cutting speed $(\mathrm{m} / \mathrm{min})$ & 63 & 188 & 314 \\
\hline B: Feed rate $(\mathrm{mm} / \mathrm{rev})$ & 0.015 & 0.15 & 0.35 \\
\hline C: Heat treatment & $\mathrm{T}_{0}$ & $\mathrm{~T}_{61}$ & $\mathrm{~T}_{7}$ \\
\hline
\end{tabular}

\section{Results and Discussion}

\subsection{Microstructure}

Generally, there was a limited solubility of Si in aluminum structures in an Al-Si eutectic system. The main phases are the Al-Si eutectic and the major alpha-Al solid solution. Figure 2a shows the microstructure of the base alloy in the as-cast condition. All phase types are clearly revealed in the microstructure. The primary Al-matrix, the eutectic silicon grains, are wide and irregular structures and the minority and asymmetrical phases of Mg2Si. For the most part, the Al-Si casting alloy proprieties were governed by the shape of the silicon particles. After a certain period of heating Al-Si-Mg alloys at elevated temperature $\left(540^{\circ} \mathrm{C}\right)$, shape irregularity in the silicon grains begin to appear until, eventually, the grains are broken down into spherical crystals. This is the fragmentation stage. Consequently, the Si grains size begins to increase due to the grain coarsening if their size is greater than the critical volume. This step is the coarsening stage, as shown in Figure 2b. With SHT, the Mg2Si is dissolved in aluminum, with the solubility depending on the temperature. Considering the different stages of heat treatment, we find that the fragmentation and coarsening stages can also occur simultaneously, in the same microstructure, depending on the variety of Si grain sizes present in the as-cast structure. Accordingly, some longer grains may be fragmented, other smaller Si grains may become spheroidized, and those already spheroidized could start coarsening, at any particular time during the solution treatment process.

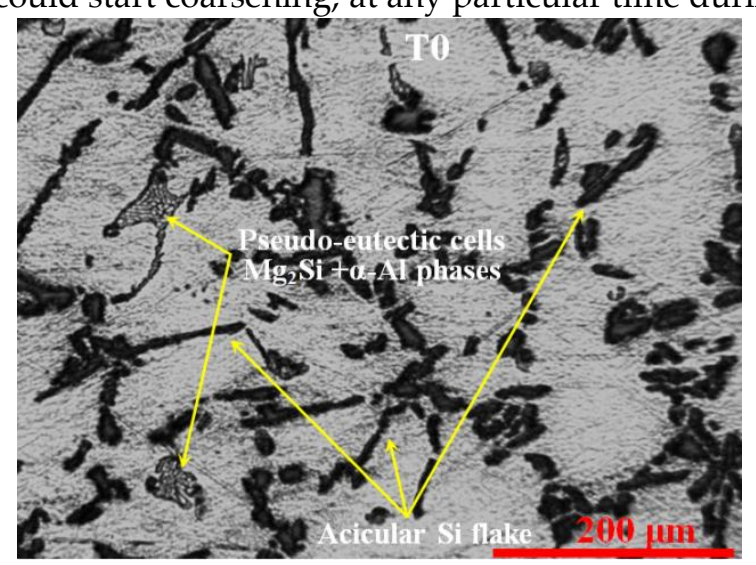

(a)

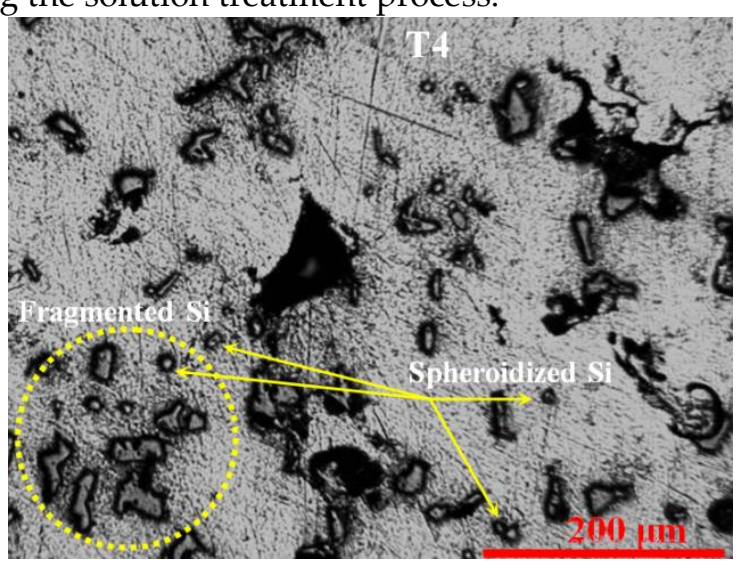

(b)

Figure 2. Effect of solution heat-treatment (SHT) on the eutectic Si particle observed in A356 in(a) A356-T0: As-received (b) A356-T4: After SHT at $540{ }^{\circ} \mathrm{C}$ for $8 \mathrm{~h}$

Al-Si alloys are heat-treated to various temperatures depending on the application requirements. The most regular heat-treatment temper for mechanical parts is the T6 for ambient service temperatures and the T7 temper for higher temperature applications. Heat-treatment results in significant microstructural changes as revealed in Figure 3. Figure3a, b shows the morphological characteristics of the Si grain observed in aged-T6 and stabilized, compared to over aged-T7 samples of A356 cast alloys. When the temperature increased to 155 and $220^{\circ} \mathrm{C}$, respectively producing T6and T7 aging, the morphology of Si particles marks the beginning of the coarsening process. In the 
A356-T6 condition, the Si particles were formed in a Rod-like manner. After applying the A356-T7 state result to the Rod-like Si particles, they undergo necking followed by fragmentation, as can be seen in Figure $3 \mathrm{~b}$ for a sample treated at $220^{\circ} \mathrm{C}$ for 5 hours. Subsequently, quenching can lock the Si particles within the aluminum matrix to form a supersaturated solid solution. In this alloy, necking and rod-like eutectic Si particles are observed. However, some of the eutectic silicon particles still possess a coarse acicular shape. The eutectic silicon particles are seen in this microstructure as large eutectic-Si particles when this microstructure is compared to as-cast. The morphological characteristics of the $\mathrm{Si}$ particle have an influence on the mechanical properties, where a transformation from an acicular to a fibrous morphology improves the mechanical properties and the ductility. The Mg2Si phase observed in the as-cast condition seem to have disappeared after heat treatment. The solution temperature is the key factor in this regard, and must be high enough that the Mg2Si can fully dissolve in solution.

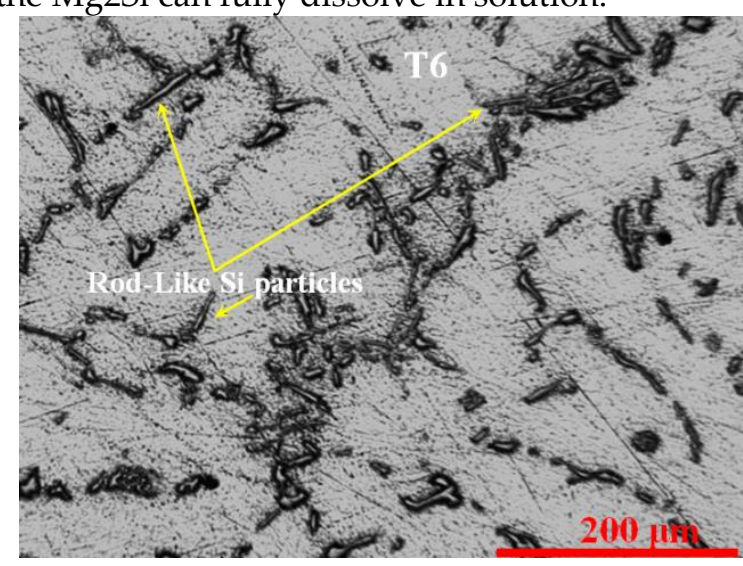

(a)

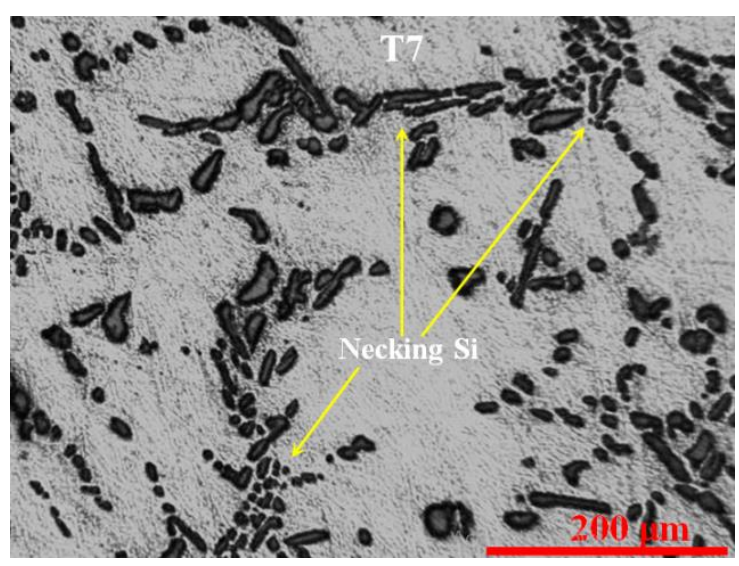

(b)

Figure 3. Effect of solution heat-treated on the eutectic Si particle observed in A356 in (a) A356-T6: solution with heat-treatment, more quenching and more artificial aging at $155{ }^{\circ} \mathrm{C}$ for 5 hours (b) A356-T7: solution with heat-treatment "SHT", more quenching and more artificial aging at $220^{\circ} \mathrm{C}$ for 5 hours

Figure 4 shows the hardness evolution during the heat treatment of the A356 aluminum alloy used in this study. The hardness measurements reveal that the maximum hardness value varies between 85 and $90 \mathrm{HRE}$. Therefore, it is supposed that aging at $155{ }^{\circ} \mathrm{C}$ for 5 hours produces almost the same precipitation hardening as aging at $180^{\circ} \mathrm{C}$ for 5 hours. Then, the hardness tends to decrease upon further aging. The variations in hardness when exposed to different aging temperatures are correlated with the number of Mg2Si phases in which the hardness increases when increasing the number of Mg2Si phases.

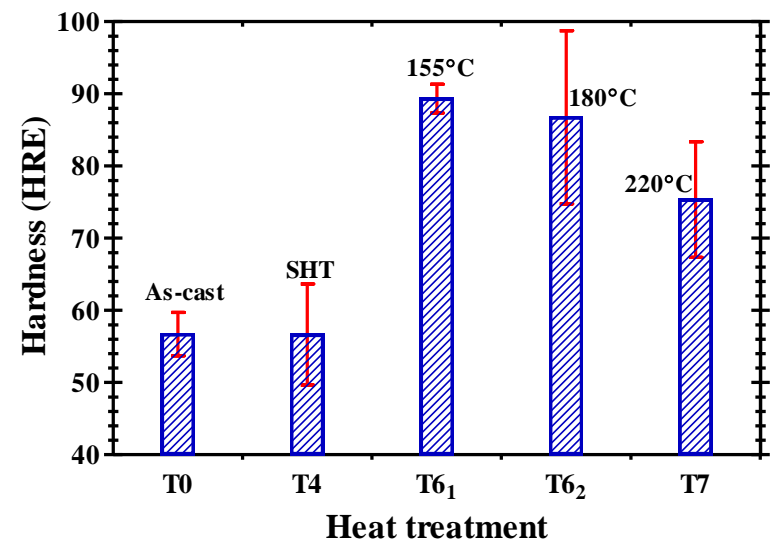

Figure 4. Hardness evolution depending on heat treatment conditions 


\subsection{Cutting Force}

Figure 5 establishes the effect of cutting speed and feed rate conditions on the cutting force during dry, mist and wet drilling applications of heat-treated A356. Cutting force variation was found to be considerably lower relative to cutting speed. The cutting speed impact is more important in increasing the cutting force value. The results also reveal that as the feed rate increases, the cutting force increases considerably. As expected, the cutting force is smaller with a lower feed. For feed rates above $0.015 \mathrm{~mm} / \mathrm{rev}$, the cutting force increases at a much higher rate. All forces are amplified with a high rate when the feed rate is extremely high. It was also found that for all feed rate and heat treatment, dry cutting engendered a higher cutting force in opposition to mist and wet modes, mostly due to the BUE on the cutting tool. In the T6 case, it was found that for all cutting speeds, wet cutting engendered a higher cutting force in opposition to dry and mist modes for the most part, due to the cutting tool wears. The wet mode influence is insignificant for the cutting force values, similar to all other factors except for the feed rate factor.

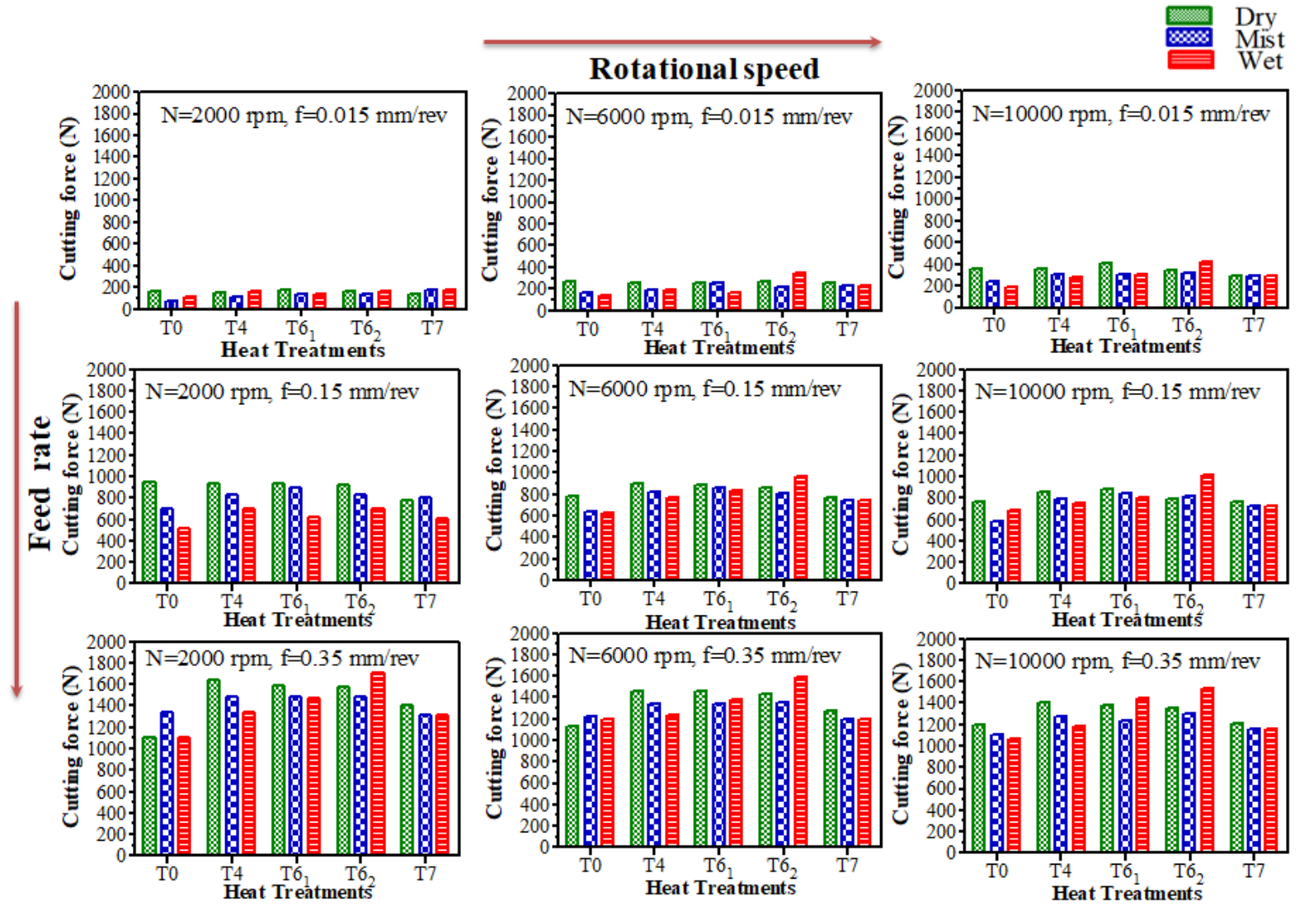

Figure 5. Effect of cutting speed and feed rate conditions on the cutting force during dry, mist and wet drilling of heat-treated A356

\subsection{Chip Characterization}

After examining the chips' morphology, we considered that segmented chips are typical for aluminum alloys, as shown in Figure 6. The chips produced by drilling the A356-T0 cast alloys have many small cracks that characterize brittle fractures (Figure 6a). Unlike A356-T4, which is more ductile, chip formation does not reveal this type of crack (Figure 6b). Compared to the case of brittle materials, deformation and friction on the chip's surface are more elevated. At the lower feed rate, the chip structure shows a high plastic deformation and it is more deformed and lengthened. Consistently, at a low feed rate the plastic strain exists over most of the chip area and the adiabatic shear is less pronounced. The chips produced by the drilling of A356-T6 show no systematic segmentation. It was noticed that the fragmentation bands are denser, as shown in Figure 6c, although the bands are strongly crushed in the heat treatment case of T7 (Figure 6d). At a higher feed 
rate, the shear strain in the primary shear zone is insignificant, which results in the smaller chip deformation. This can be explained by the medium thermal conductivity of aluminum, which leads to an increase in shear plane temperature and softening of the material, and these results in more strain in the same shear plane. Furthermore, at a higher feed, the bulk of the segment seems to be displaced with elevated strain at the adiabatic shear zone, and very small strain in the bulk of the segment area. In this situation, the chip formation has a cyclic segment and adiabatic shear lines delimiting each segment.

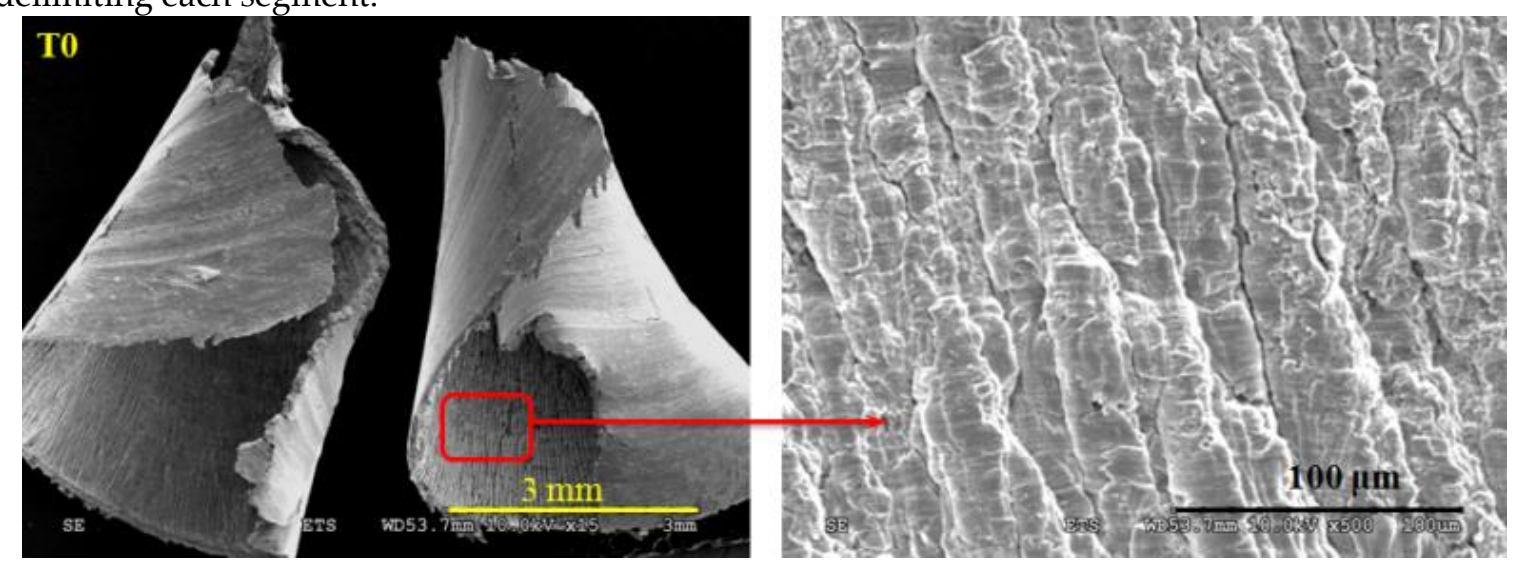

(a)

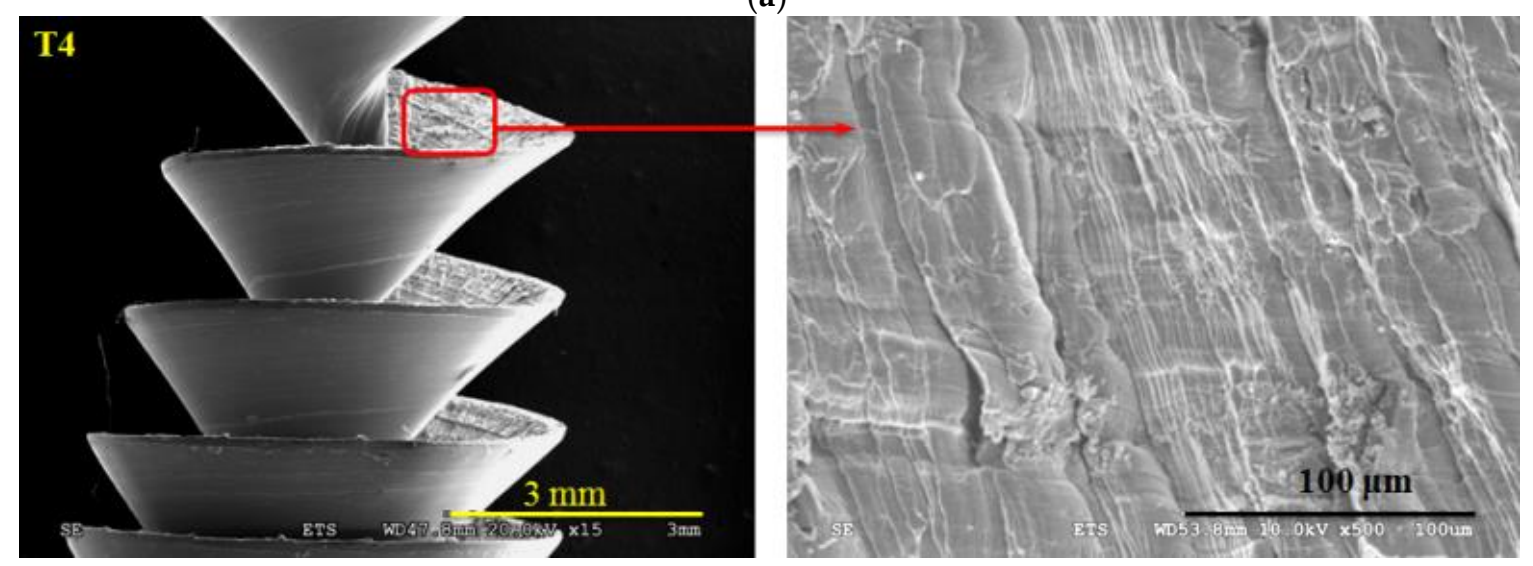

(b)

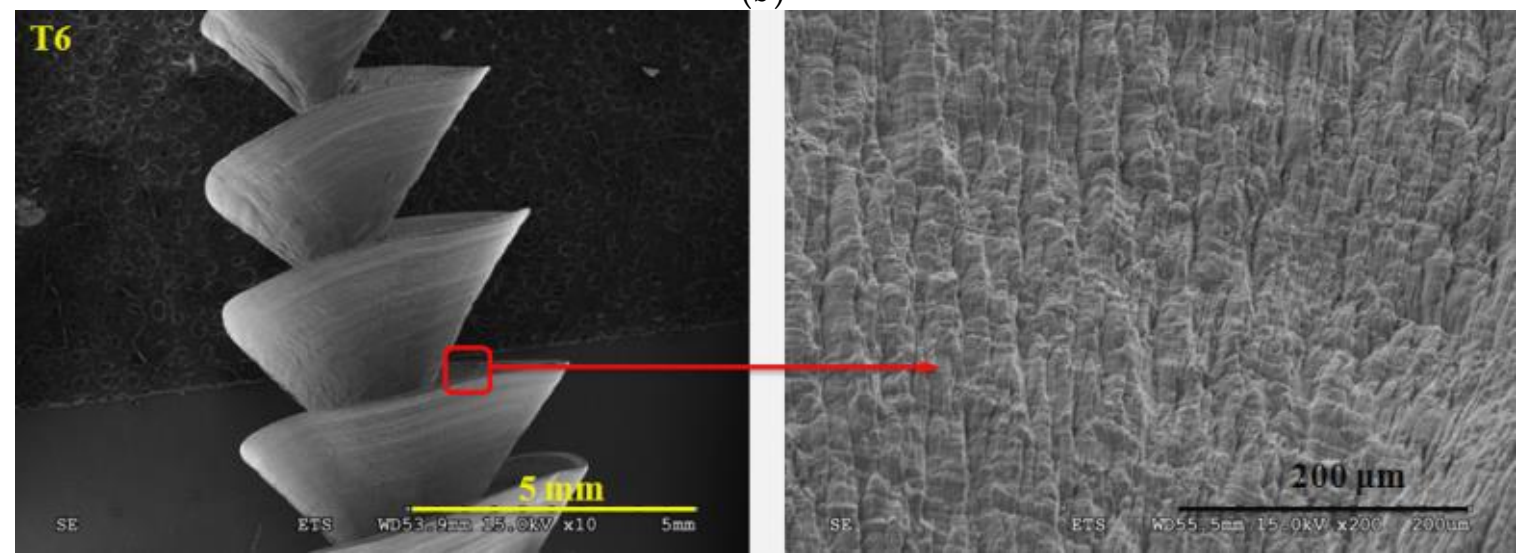

(c) 

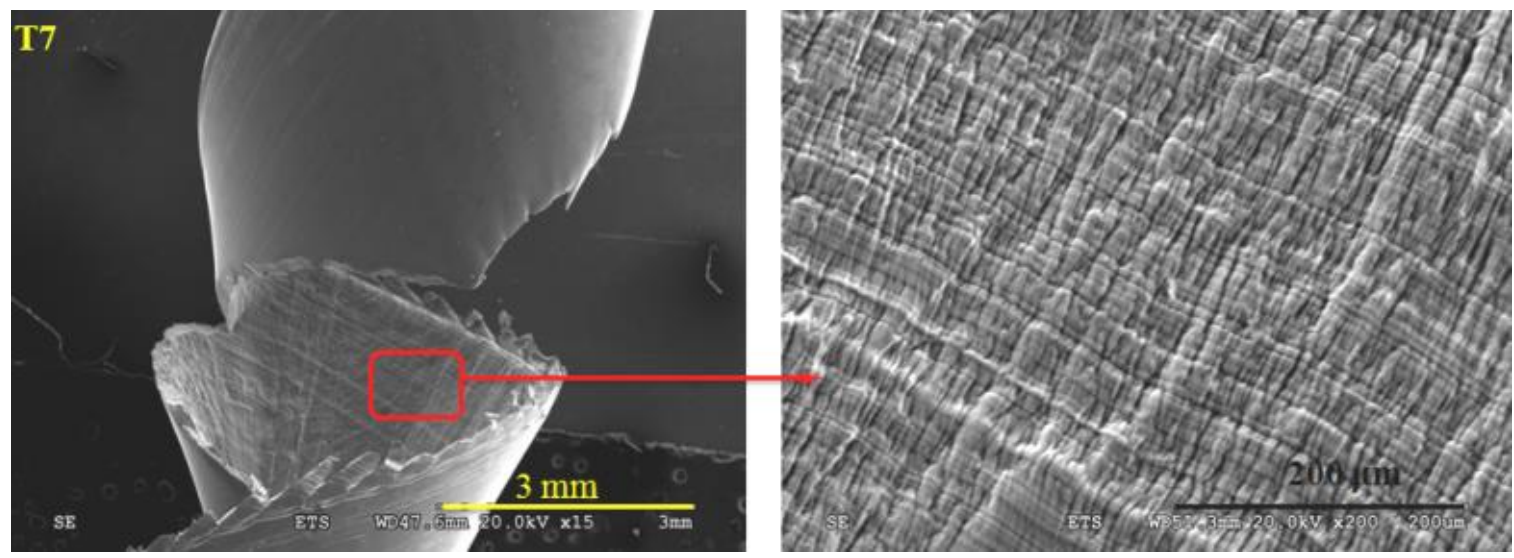

(d)

Figure 6. Effect of heat treatment on chip segmentation produced by the drilling of the A356 for a rotational speed of $6000 \mathrm{rpm}$ and feed rate of $0.15 \mathrm{~mm} / \mathrm{rev}(\mathbf{a})$ As-received (b) After SHT at $540{ }^{\circ} \mathrm{C}$ for $8 \mathrm{~h} \mathrm{(c)} \mathrm{at} 155^{\circ} \mathrm{C}$ for 5 hours (d) at $220^{\circ} \mathrm{C}$ for 5 hours

Drilling is performed with uncoated HSS twist drills. The measurement of the chip-forming effect is specified by the chip compression ratio. The significance of the chip compression ratio is to provide information on the rate of plastic deformation and evaluate the temperature distribution in the chip formation zone during the drilling process, in our case. An elevated shear angle indicates a lower chip compression ratio value, which is reflected by a low strain in the chip and reduced energy consumption. The chip compression ratio is the ratio of the chip thickness to the depth of the cut (Equation (1)). Tool geometry was designed to remove a cut with the thickness h1 (uncut chip thickness) and the produced chip has a thickness of h2 (actual chip thickness). The chip compression ratio $\zeta$ can be defined as

$$
\zeta=\mathrm{h} 2 / \mathrm{h} 1
$$

Figure 7a,b shows the effect of cutting speed and feed rate on the chip compression ratio in dry, mist and wet drilling of heat-treated A356. Commonly, the chip compression ratio drops drastically with increasing artificial aging temperature (T61). Then, it increases according to this artificial aging temperature (T62, T7). The values of the chip compression ratio for the same feed rate are very close for all the cutting speeds studied. The scatter in the chip compression ratio with increasing cutting speed is not high for the same feed rate. On the other hand, there is a considerable decrease in chip compression ratio with increasing feed rate. It is also noted that large values of feed rate result a decrease in the chip compression ratio due to the decrease in the plastic deformation zone. The variation in the chip compression ratio for the identical cutting speed of drilling of the A356 as-received is achieved after heat-treatment in solution and T61. In the T62 and T7 conditions, the decrease in chip compression ratio is low and has a tendency to increase. Lubrication modes must be chosen based on the drilling parameters used for a given combination of tools and material. However, for the mist lubricant mode, the chip compression ratio shows two different evolutions for the three feed rates used. For low values of feed rates, the chip compression is significant for mist compared to other lubrication modes. On the other hand, for high values of feed rates, the chip compression is significant for dry, compared to other, lubrication modes. This is attributed to the chip segmentation, as discussed earlier (adiabatic shear and plastic strain). The variation in the chip compression ratio is more pronounced for lower feed rates and for various cutting speeds. The contact length between the tool and the chip is greatly increased when the feed rate is increased. In addition, the friction coefficient value decreases as the cutting speed increases, due to the increase in tool-chip contact, which produces a thermal softening and thus decreases the friction coefficient. Therefore, it is evident that the tool-chip friction contact decreased as the cutting speed and feed rate increased for all cases. However, an elevated ratio of chip compression at a low feed rate increases the normal load, which increases the friction coefficient. Under these conditions, the effect of the feed rate plays a central position in drilling performance. 


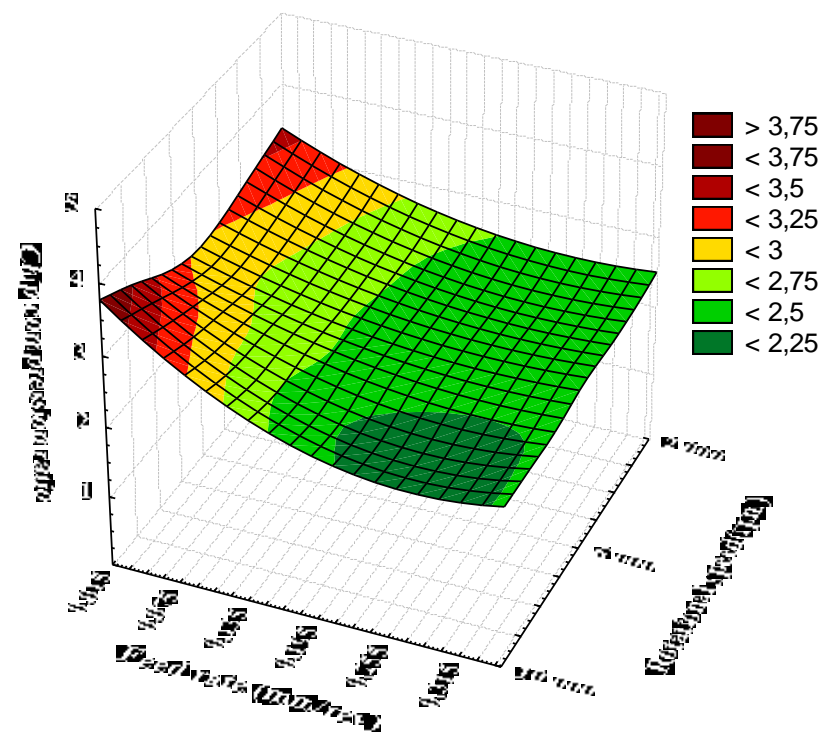

(a)

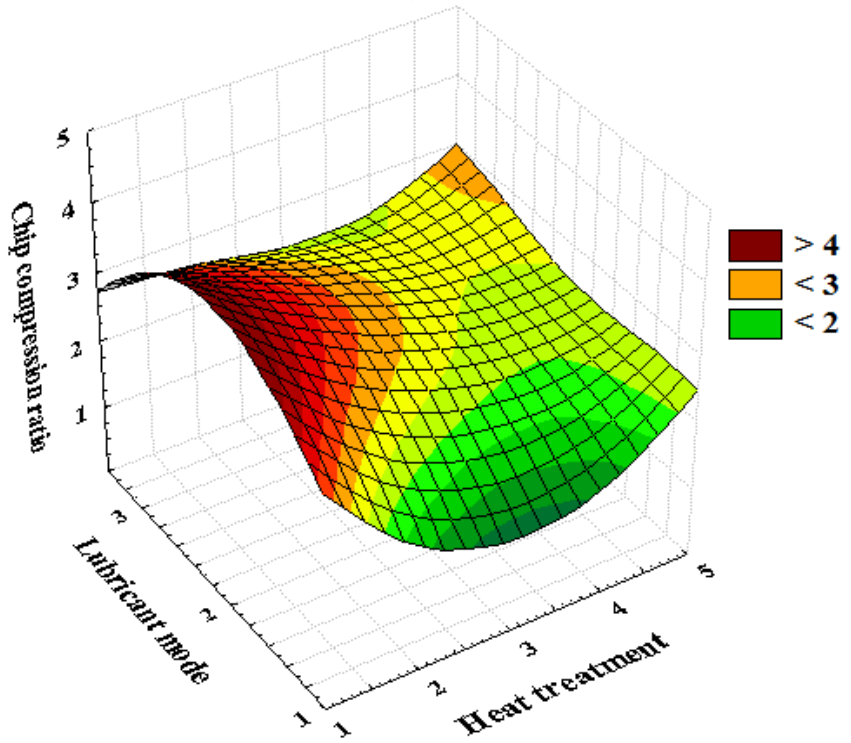

(b)

Figure 7. (a) Control of cutting speed and feed rate on chip compression ratio, (b) Control of dry, mist and wet drilling of heat-treated A356 on chip compression ratio

\subsection{Surface Quality}

The surface finish of the machined parts is a very important result in mechanical manufacturing. This aspect affects the mechanical parts' performance and fabrication costs. In addition, the topography and texture of the machined surface are used more as an indication of variation in the tool wear, machine tool vibration, and the detection of damaged machine components. Figure 8 shows the topography of a reconstructed three-dimensional hole surface. Roughness includes the finest irregularities of a particular production process or material condition surface. Average roughness $(\mathrm{Ra})$ is the gap between the roughness profile and its centerline, or the function between the absolute value of the roughness profile height and the evaluation length. 


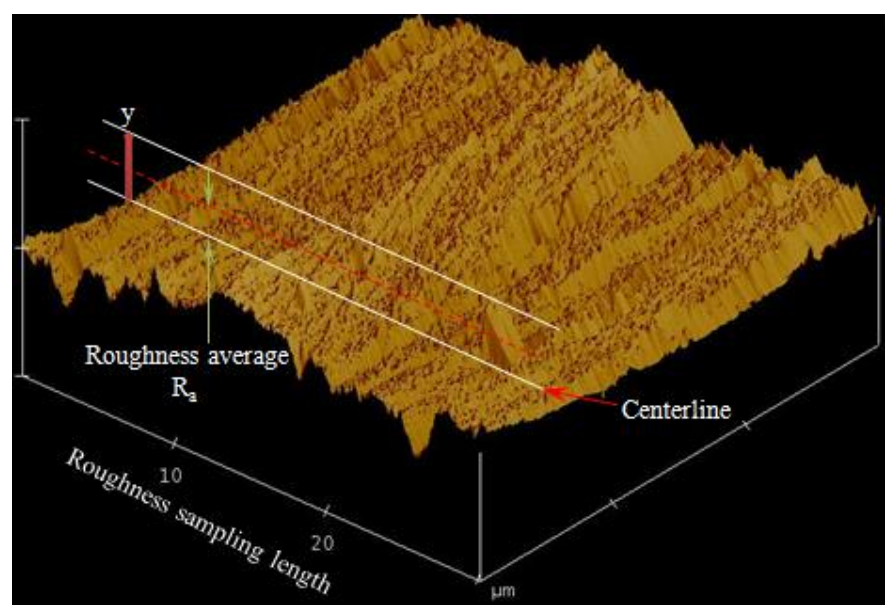

Figure 8. Surface topography and texture during dry drilling of the A356-T0 at $6000 \mathrm{rpm}$ and 0.15 $\mathrm{mm} / \mathrm{rev}$

Figure9 show the generated surfaces by drilling of A356 for cutting speed of $6000 \mathrm{rpm}$ and a feed rate of $0.15 \mathrm{~mm} / \mathrm{rev}$. In drilling, the tool leaves spiral marks on the machined surface (feed marks). The comparison between different feeds with the same tool shows that the larger feed increases the separation between feed marks, which leads to an increase in the value of the geometric surface roughness. The feed is the main influence on the surface finish obtained. It has been found that the lowest feed values give a cheap finish due to a very small chip thickness, which leads to poor surface formation. Asymmetrical roughness due to plastic deformation was observed when drilling A356 at low cutting speeds. After exceeding a certain value of cutting speed, the irregular roughness disappears. Surface roughness at low cutting speeds is influenced by surface plastic deformation and BUE formation. The cutting speed is the parameter which has a great influence on the roughness, due to the processed material's contribution to the machining process. It becomes dominant in the presence of a BUE and discontinuous chip.
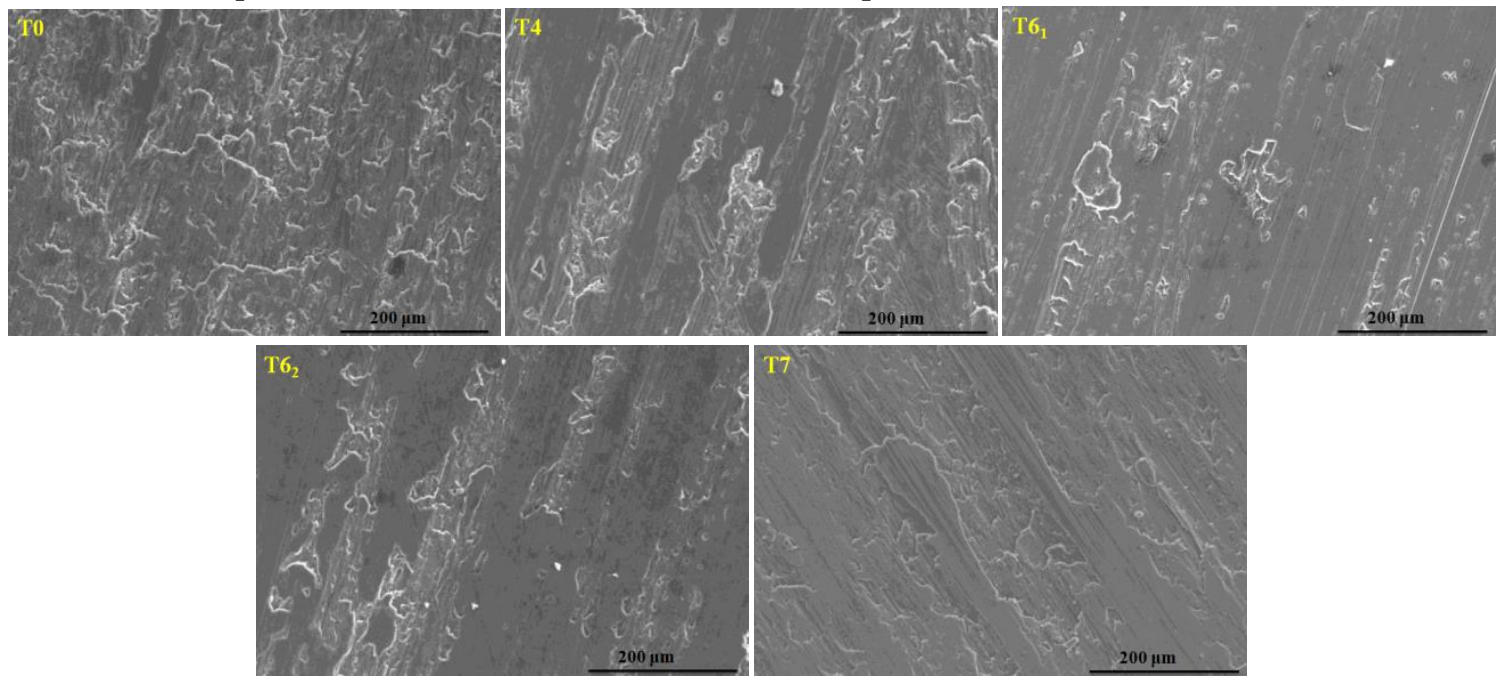

Figure 9. Surface quality on A356 during dry drilling, for cutting speeds of $6000 \mathrm{rpm}$ and feed rate of $0.15 \mathrm{~mm} / \mathrm{rev}$, as observed with a SEM

The surface roughness values (Ra) of the drilled hole are shown in Figure 10; they are measured parallel to the feed direction. It is evident that surface roughness depends on the machining factors employed each time, which is a complex problem in the drilling process. Commonly, surface roughness is affected by two main factors: the feed and the tool geometry (nose radius). However, in an actual situation as for A356, lubricant modes and heat treatment conditions affect the roughness of machined surfaces. This effect is due to the alteration in parts-tool interactions and the chip 
formation process. From Figure 10, it is confirmed that with an increase in the artificial aging temperature, the values of surface roughness (Ra) are less important. Therefore the heat treatment state is a dominant parameter and has more effect on Ra. The heat-treatment condition has a much steeper slope than the lubricant modes and it has also observed that the surface roughness showed a variation with the difference in the lubrication mode. As shown clearly in Figure 10, the wet and mist drilling reveal a smoother surface, while the dry conditions result in increased roughness. This last condition produces heavily deformed zones on the side-wall with significant feed marks. However, for artificial aging T7, the surface roughness values of holes drilled under wet drilling are almost four times higher than those under mist and dry drilling. It is very important that a wet application was found to have an undesirable effect on the finish of the hole surface. The particular surface effects observed during wet drilling may can be explained by the phenomena of chips dragging against the side wall of the hole as the drill was retracted. The application of high-pressure lubrication has trapped the chip within the tool flute, which suggests that high-pressure lubrication is not very efficient. The finest surface quality can be achieved under artificial aging T6 and wet application. Except the artificial aging T7, the finest surface quality results under dry drilling rather than that observed in wet and mist drilling.

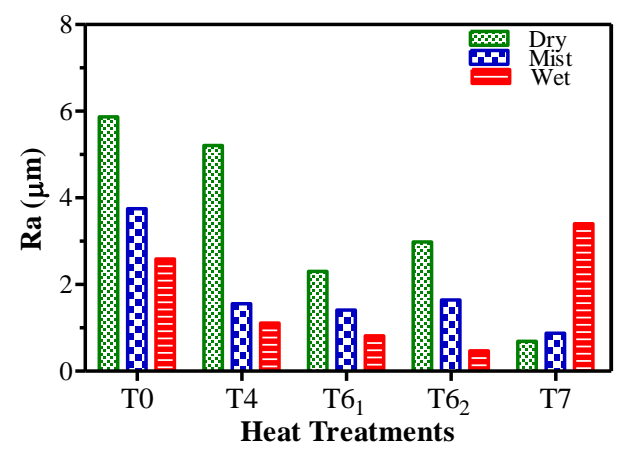

(a)

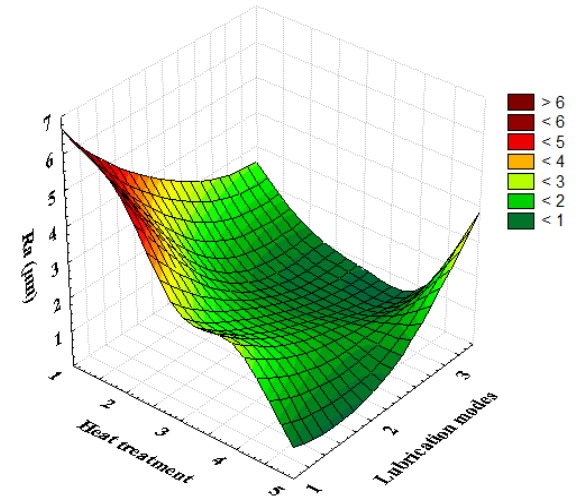

(b)

Figure 10. (a) $R_{a}$ variation under various heat treatments, (b) $R_{a}$ variation under various heat treatments and lubrication modes during drilling of the A356 at $6000 \mathrm{rpm}$ and $0.15 \mathrm{~mm} / \mathrm{rev}$

\subsection{Burr Formation}

In the drilling process, the material extends over the machined surface to exit the edges of the part and generates burrs. As a result, most of the burrs are found on the exit surface while the entrance surface of the hole shows small or no burrs. In this case, very small burrs were found on the hole edges. These small burrs can be explained by noting that, in drilling, the chip load is small at the beginning and end of the cut, leading to more rubbing instead of cutting. In this study, for different cutting speeds and feed rates, the most common burr type observed was a homogeneous burr with a uniform thickness (Figure 11).

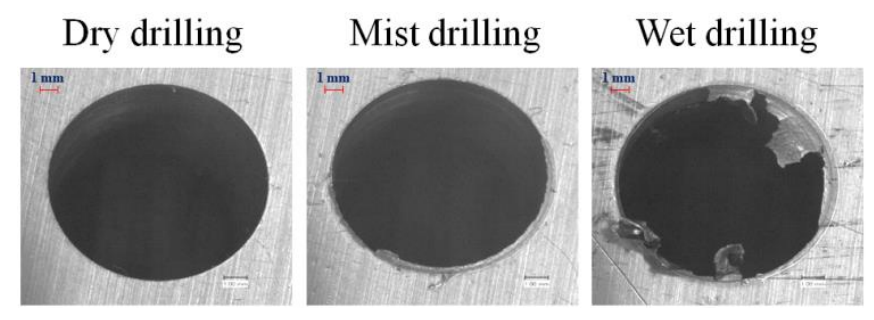

Figure 11. Influence of different cutting fluids on burr formation during the drilling of an A356-T6 alloy

Figure 12 shows the burr type generated at different heat treatments and cutting speeds during the dry drilling of an A356 alloy for a feed rate of $0.35 \mathrm{~mm} / \mathrm{rev}$. The results show that heat-treatment has significant effects on burr height. Figure 13 shows that burr height decreases with T6 heat 
treatment and then increases with T7 heat treatment. Figure 11 also shows that the use of lubricated drilling (mist and wet modes) generates larger burrs compared to dry drilling. Chips formation associated with plastic strain is intensified; this intensification affects the size of the burrs. This is due to the effect of a cutting fluid which trims down the temperature in the drilling zone, making the process of chip evacuation very difficult. On the other hand, using dry cutting condition decreases the burr height. The results show that the heat treatment and the cutting fluid have distinctive effects on burr size.

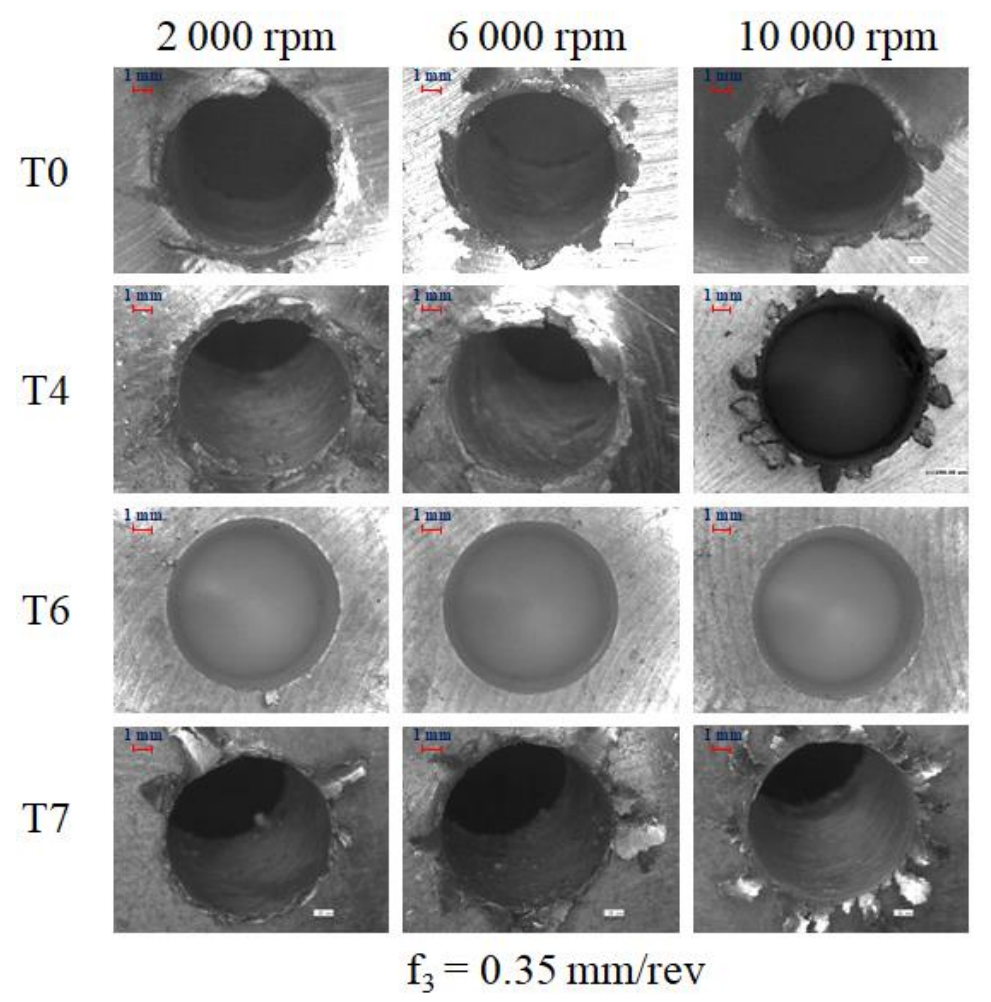

Figure 12. Effect of heat treatments during dry drilling of an A356 alloy at different cutting speeds on burr formation

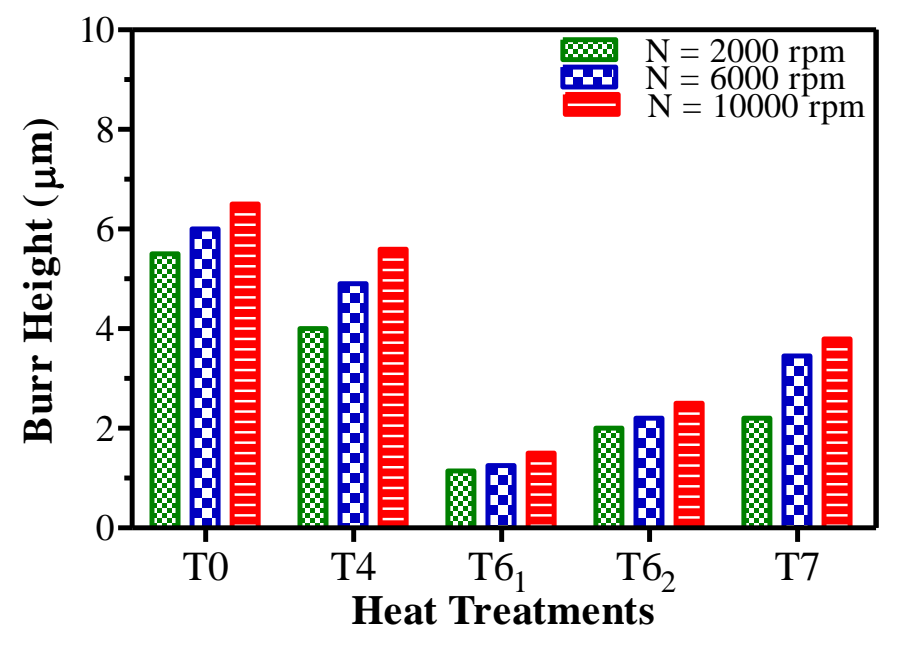

Figure 13. Burr height under various heat treatments at feed rate $0.35 \mathrm{~mm} / \mathrm{rev}$ 


\subsection{Tool Wear}

Figure 14 show samples of tool flank-wear and BUE formation. In all of the experiments carried out, the major form of tool failure when drilling A356 was flank wear (Figure14). The abrasive wear process while drilling A356 is not at all different from the usual tool wear processes when machining metal. This is due to the Si particle abrasion on the tool surfaces during drilling. The major difference observed is the number of Si particles and the size, produced by the different solution treatment temperatures, which are of interest regarding tool wear. However, the tool flank-wear was insignificant at the cutting edge. The BUE from dry drilling of the A356 matrix, which is usually soft and ductile, is seen in tool flank.
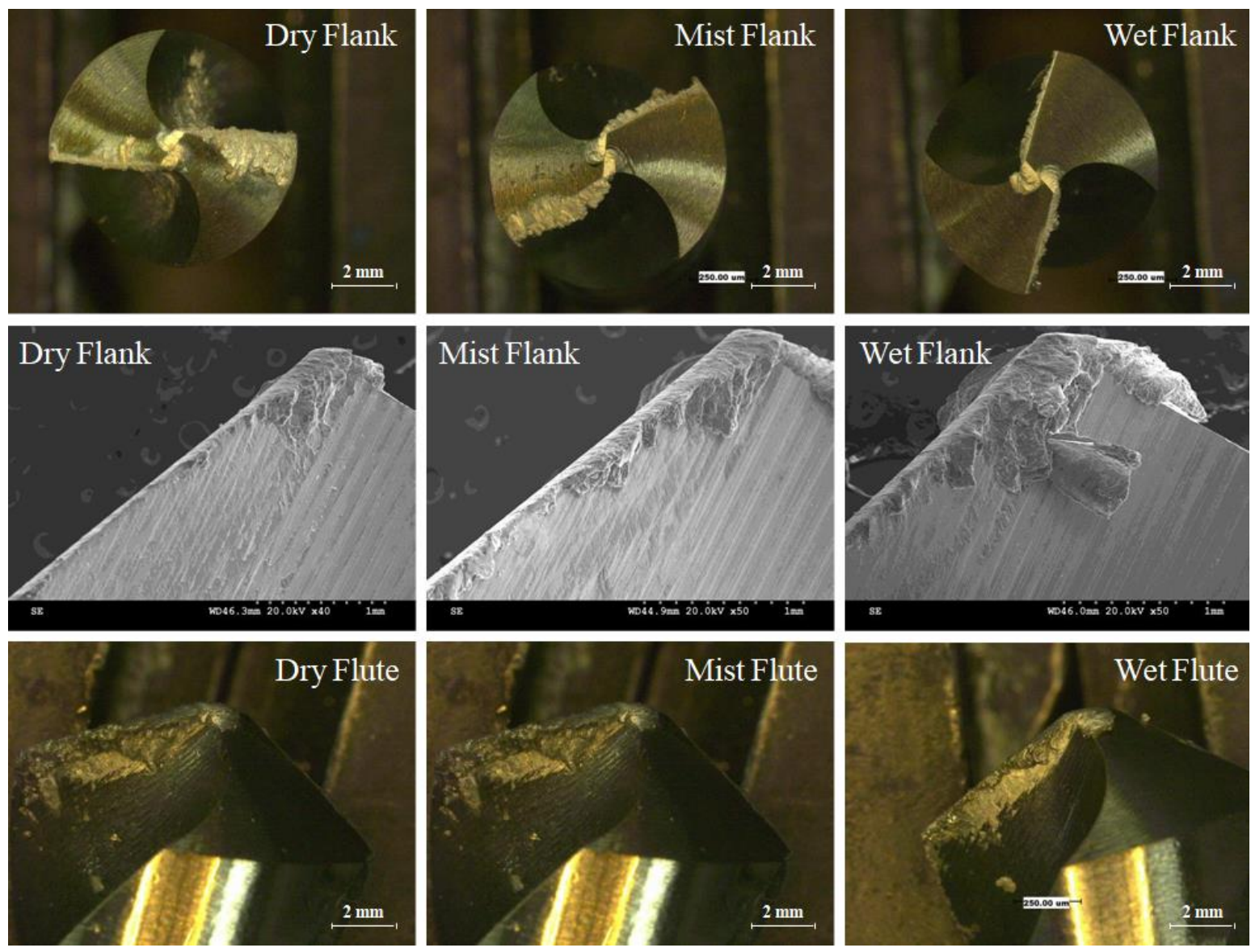

Figure 14. Samples of tool flank-wear and BUE formation

\section{Conclusions}

Drilling tests were carried out on the as-received and SHT workpieces with different hardness values, which resulted from different aging procedures after solution heat-treatment. The following conclusions were found in experiments conducted to study the effects of heat-treatment and lubrication modes on the machinability of Al-Si-Mg cast alloys:

- Hardness is one of the most important metallurgical parameters that can control the alloy machinability. A further increase in the aging temperature to $180^{\circ} \mathrm{C}$ decreases the hardness of the alloy;

- Chip formation depends on the heat-treatment conditions of the material of the part. Feed rate had the strongest impact on chip formation. The best chip formation was for a feed rate at $0.35 \mathrm{~mm} / \mathrm{rev}$, dry drilling and artificial aging at T6;

- Heat treatment strongly controls the burr formation and surface quality;

- Cutting forces and surface roughness are among the most important machinability criteria. At a low cutting speed, we have a better performance of dry drilling and a longer tool life; 
- When drilling, better lubrication in the cutting zone can increase tool life and improve surface finish;

- The finest surface quality results when artificial aging at T6 and wet drilling are present.

Considering that the surface finish of a drilled hole wall was the most important criterion for drilling process quality, the optimization of cutting conditions for this criterion will be achieved by a high feed rate, wet drilling and artificial aging at T6. Although the costs for the tools rise, it is still more cost-efficient to use more tools than cutting fluids. It is preferable to use dry drilling, which generates a higher shear angle (low chip compression ratio). This means a reduction in energy consumption and strain in the chip.

\section{Author Contributions:}

Conceptualization, A. Djebara.; methodology, A. Djebara.; software, M.A. Alliche.; validation, A. Djebara., Y. Zedan., M.A. Alliche and V. Songmene.; formal analysis, M.A. Alliche.; investigation, A. Djebara., Y. Zedan.; resources, V. Songmene.; data curation, A. Djebara., Y. Zedan.; writing-original draft preparation, M.A. Alliche.; writing-review and editing, A. Djebara.; visualization, A. Djebara., Y. Zedan., M.A. Alliche and V. Songmene.; supervision, A. Djebara.; project administration, V. Songmene.; funding acquisition, V. Songmene."

\section{Funding:}

This research received no external funding

\section{Conflicts of Interest:}

The authors declare no conflict of interest.

\section{References}

1. Akram, S.; Imran, H.; Khan, M.; Mubashar, A.; Warsi, S.; Riaz, U.A numerical investigation and experimental validation on chip morphology of aluminum alloy 6061 during orthogonal machining. In Proceedings of the 2016 Moratuwa Engineering Research Conference (MERCon), Moratuwa, Sri Lanka, 5-6 April 2016; pp.331-336.

2. Zedan,Y.; Samuel,F.; Samuel,A.; Doty,H. Effects of Feinter metallics on the machinability of heat-treated Al-(7-11)\%Si alloys. J. Mater. Process. Technol. 2010, 210, 245-257.

3. Songmene, V., Khettabi, R., Zaghbani, I., Kouam, J., \& Djebara, A. (2011). Machining and machinability of aluminum alloys. Alum. Alloys Theory Appl.

4. Demir, H.; Gündüz, S. The effects of aging on machinability of 6061 aluminum alloy. Mater. Des. 2009, 30, 1480-1483.

5. Fratila, D.; Popan,A. Analysis and Optimization of Cutting Parameters in Drilling Operation of EMAW-2007 Aluminum Alloy. Acad. J. Manuf. Eng. 2018, 16, 1.

6. Baliga, B.D.; Mohandas, K.N.; Kumar, T.A. Study of machinability and corrosion behavior of Al-Si-Mg alloy treated with master alloys. Int. J. Eng. Sci. Inn. Technol. 2015, 4, 310-316.

7. Songmene, V.; Masounave, J.; Balout, B. Clean Machining: Experimental Investigation on Dust Formation Part II: Influence of Machining Parameters and Chip Formation, Part II. Int. J. Environ. Conscious Des. Manuf. 2008, 14, 17-33.

8. Saunders, L.K.; Mauch, C.A. An exit burr model for drilling of metals. J. Manuf. Sci. Eng. 2001, 123, $562-566$.

9. Lauderbaugh, L. Analysis of the effects of process parameters on exit burrs in drilling using a combined simulation and experimental approach. J. Mater. Process. Technol. 2009, 209, 1909-1919.

10. Aurich, J.C.; Dornfeld, D.; Arrazola, P.J.; Franke, V.; Leitz, L.; Min, S. Burrs-Analysis, control and removal. CIRP Ann. Manuf. Technol. 2009, 58, 519-542.

11. Sofronas, A.S. The Formation and Control of Drilling Burrs. Ph.D. Thesis, University of Detroit, Detroit, MI, USA, 1975.

12. Hasegawa, Y.; Shigio, Z.; Akiyasu, Y. Burrs in Drilling and Prevention of it. Tech. Pap. Soc. Manuf. Eng. 1975, 01, 75-480.

13. Pande, S.; Relekar, H. Investigations on reducing burr formation in drilling. Int. J. Mach. Tool Des. Res. 1986, 26, 339-348. 
14. Ko, S.-L.; Lee, J.-K. Analysis of burr formation in drilling with a new-concept drill. J. Mater. Process. Technol. 2001, 113, 392-398.

15. Shivkumar, S.; Ricci, S.; Steenhoff, B.; Apelian, D.; Sigworth, G. An experimental study to optimize the heat treatment of A356 alloy. AFS Trans. 1989, 97, 791-810.

16. Hetke, A.; Gundlach, R. Aluminum casting quality in alloy 356 engine components. Am. Foundry Men's Soc. 1994, 102, 367-380.

17. Gillespie, L.R.K. Deburring Technology for Improved Manufacturing; Society of Manufacturing Engineers (SME): Dearborn, MI, USA, 1981.

18. Ko, S.-L. Measurement and effective deburring for the micro-burrs in piercing operation. Int. J. Precis. Eng. Manuf. 2000, 1, 152-159.

19. Wang, Q.; Cáceres, C.H. Mg effects on the eutectic structure and tensile properties of Al-Si-Mg alloys. In Proceedings of the Materials Science Forum, Grenoble, France, 1996.

20. Djebara, A.; Zedan, Y.; Kouam, J.; Songmene, V. The effect of the heat treatment on the dust emission during machining of an Al-7Si-Mg cast alloys. J. Mater. Eng. Perform. 2013, 22, 3840-3853.

21. Callister, W.D.; Rethwisch, D.G. Materials Science and Engineering: An Introduction; Wiley: New York, NY, USA, 2007.

22. Jorstad, J. Machinability of 380 alloys: Effect of minor elements and impurities. Trans. Soc. Cast. Eng. 1979, $79,72$.

23. Jorstad, J. Influence of aluminum casting alloy metallurgical factors on machinability. SAE Trans. 1980, 79, 1892-1906.

24. Burant, R.; Skingle, T. Machining the Silicon-Containing Aluminum Alloys; SAE Technical Paper: Detroit, Michigan, USA, 1980.

25. Kelly, J.; Cotterell, M. Minimal lubrication machining of aluminum alloys. J. Mater. Process. Technol. 2002, 120, 327-334.

26. Braga, D.U.; Diniz, A.E.; Miranda, G.W.; Coppini, N.L. Using a minimum quantity of lubricant (MQL) and a diamond coated tool in the drilling of aluminum-silicon alloys. J. Mater. Process. Technol. 2002, 122, 127-138.

27. Klocke, F.; Eisenblätter, G. Dry cutting. Cirp Ann. Manuf. Technol. 1997, 46, 519-526.

28. Zedan, Y.; Niknam, S.; Djebara, A.; Songmene, V. Burr Size Minimization When Drilling 6061-T6 Aluminum Alloy. In Proceedings of the ASME 2012 International Mechanical Engineering Congress and Exposition, Houston, TX, USA, 9-15 November 2012.

29. Khettabi, R.; Nouioua, M.; Djebara, A.; Songmene, V. Effect of MQL and dry processes on the particle emission and part quality during milling of aluminum alloys. Int. J. Adv. Manuf. Technol. 2017, 92, 2593-2598.

30. Chatha, S.S.; Pal, A.; Singh, T. Performance evaluation of aluminum 6063 drilling under the influence of nano-fluid minimum quantity lubrication. J. Clean. Prod. 2016, 137, 537-545.

31. Niknam, S.A.; Zedan, Y.; Songmene, V. Machining Burrs Formation \& Deburring of Aluminum Alloys. Light Met. Alloy. Appl. 2014, 1, 99-122.

32. Sreejith, P.; Ngoi, B. Dry machining: Machining of the future. J. Mater. Process. Technol. 2000, 101, $287-291$.

33. Basavarajappa, S.; Chandramohan, G.; Narasimha Rao, K.V.; Adhakrishanan, R.; Krish, V. Turning of particulate metal matrix composites-Review and discussion. In Proceedings of the Institution of Mechanical Engineers, London, United Kingdom, July2006. 